Rev Biomed 2003; 14:279.

\title{
Los sueños como expresión de nuestros deseos.
}

Carta al Editor

Jesús Quintanilla-Osorio.

Coordinación de Regulación sanitaria. Servicios estatales de salud de Quintana Roo, Chetumal, Quintana Roo, México.

De acuerdo a Sigmund Freud, los sueños constituyen una manifestación de nuestros deseos, donde la propia censura de la sociedad, con sus reglas morales y sociales, ha limitado su tratamiento a una exposición más íntima, más privada de ellos.

Señalaba Freud, al referirse a los sueños: "Por su carácter de realización de deseos, se dividen en tres clases: en primer lugar, aquellos que muestran francamente un deseo no reprimido. En segundo, los que exteriorizan disfrazadamente un deseo reprimido; esto es, la mayoría de los que necesitan del análisis. $\mathrm{Y}$ en tercer lugar, aquellos otros que, si bien representan un deseo reprimido, lo hacen sin disfraz alguno o con un disfraz insuficiente"(1)

Es decir, que los sueños, esas experiencias oníricas que nos dejan perplejos porque las más de las veces no los entendemos, son traducciones exactas de esos deseos, pero requieren de una interpretación, y la llave de la hermenéutica para conocer sus misterios reside en nuestro yo interno.

Traducirlos, de un lenguaje y experiencia comprensibles a nuestro idioma más simple y sencillo, es una tarea ardua. Significa relacionarlos con la llamada "elaboración del sueño", proceso mental donde funcionan alternativamente la represión, el desplazamiento y la condensación, dando lugar a la dramatización misma de este viaje onírico, para comprender cabalmente su estructura y desenredarlos de la madeja de misterio en la cual se envuelven durante el día.

Así, por ejemplo, los sueños infantiles muchas veces representan situaciones que los infantes no completaron y hubieran deseado terminar. Freud cita numerosos ejemplos de chiquillos soñando con la conclusión de una experiencia inacabada. En cambio, los adultos soñamos transmutando esos deseos internos que pujan por salir de nuestra "caja negra", (cual si fuéramos un avión en vuelo registrando los sucesos del viaje), en representaciones que pueblan nuestras mentes por las noches.

Darles su justo y cabal significado depende del análisis al cual los sometamos, de la dosis de sinceridad utilizada y de estar abiertos a entender estas experiencias sin temer ruborizarnos por sus implicaciones.

Palabras clave: Sueños, sicoanálisis.

\section{REFERENCIA.}

1.- Freud, S. Los sueños. México, D.F. Alianza Editorial; 1994.p. 71.

Solicitud de sobretiros: Jesús Quintanilla-Osorio, Tlaxcalatongo 250 entre Carranza y San Salvador, Colonia Venustiano Carranza, C.P. 77012, Chetumal, Quintana Roo, México. 